of sky and solar radiation at different stages of the eclipse. Curves of these are given, which indicate that the sky radiation varies proportionally to the amount of sunlight.

Prof. Bauer then discusses the British expeditions and the observed deflection of light. As these have already been dealt with in NATURE (November I3, I919, and elsewhere), it will suffice to mention one paint. After noting that the Sobral results indicated larger deflection than those deduced from Einstein's law, and that the excess was greater in R.A. than in declination, Prof. Bauer made the suggestion that the excess might arise from the passage of the light through a rare outer atmosphere of the sun, which, like the corona, might be more extended in the equatorial regions. The residuals are too small to lay very much stress on this, unless future eclipses should indicate the same effect.

\section{The Manufacture of Synthetic Ammonia and Production of Nitrates.}

THE Ministry of Munitions announces that Lord Inverforth has arranged for the sale of H.M. Nitrate Factory at Billingham-on-Tees to Messrs. Brunner, Mond, and Co., Ltd. The purchasers will form a company to take over the factory, and will be responsible for all outstanding liabilities of the Ministry in connection with the project. This factory, the erection of which was commenced early in 19 is by the Department of Explosives Supply, was designed for the manufacture of synthetic ammonia and for the production of 60,000 to 70,000 tons of ammonium nitrate annually.

Soon after the appointment of the Nitrogen Products Committee, the monumental report of which was published in January last, the Government decided to install one or other of the processes for the fixation of nitrogen. The Committee, after thorough investigation of the problem, recommended the cyanamide process as the one best suited for this purpose in the circumstances, since the working details were well understood. This advice was at. first adopted, and a contract was on the point of being negotiated, but, for reasons which are not stated, the recommendation was not acted upon.

During I9I6 the Nitrogen Products Committee had established a laboratory in premises placed at its disposal in the new Ramsay building of University College, London, and the Committee's research staff, under the direction of Dr. J. A. Harker, was engager in an experimental investigation of a number of problems relating to nitrogen fixation. Although it was not anticipated that there would be any shortage of supplies of ammonia, yet it was deemed desirable, in view of the special suitability of the synthetic ammonia process for the needs of this country, that an experimental study of it should be made forthwith, so that the required information should be available if necessary.

After a year's experimental work, the progress made was considered so encouraging that the Committee decided to establish a moderate-sized technical trial unit, and funds for the purpose were allocated by the Treasury. It was hoped, by means of this plant, that a study of the chemical engineering problems could follow upon that already made of the pure chemistry of the reactions involved, but the Committee did not suggest the establishment of the process as a war measure upon an industrial scale. In to17, however, the Explosives Supply Department considered that the position reached in the experiments justified it in recommending the erection of a large works, in substitution for the Committee's cyanamide project, and NO. 2636 , voL. IO5] a site at Billingham, some 260 acres in extent, was ultimately chosen for this purpose. But a number of dificulties supervened, and construction was slow, and at the time of the Armistice only a few permanent buildings and a number of temporary structures had been erected, though a large amount of plant had been ordered.

The purchasers of the factory now undertake to complete the scheme by providing the additional buildings and plant required for the synthesis of ammonia and its oxidation to nitric acid and nitrates suitable for the manufacture of explosives and fertilisers.

It is understood that the company has acquired a large amount of additional land and that it intends to develop the project on a very large scale. 'The factory has been re-designed on a peace as distinct from its former war basis, and in many particulars the new plant will represent a substantial advance, both in the ammonia and nitric acid sections, on anvthing previously used in Germany.

\section{New Ordnance Survey Maps.}

THE new edition of the one-inch and quarter-inch Ordnance Survey maps is described, with specimen sheets, by Lt.-Col. W. J. Johnston in the Geographical Journai for March (vol. Iv., No. 3). Three types of one-inch map are to be published: the popular, the district tourist, and the outline. The popular edition has contours in orange at $50-\mathrm{ft}$. vertical interval in place of the $100-\mathrm{ft}$. and $250-\mathrm{ft}$. interval on the former one-inch maps. A new classification of roads, which divides them into ten categories, makes the main roads, coloured red, stand out prominently. Rivers and streams are shown in solid blue. Parish boundaries, which caused much confusion with footpaths, are omitted, but county boundaries are retained. Woods are coloured green. The outline edition is the present one-inch map, which in future will be printed from stone on stout paper. The tourist edition entails a combination of sheets to cover conveniently in one map certain areas frequented by holiday-makers. It is hoped to have at least eight of the tourist sheets ready before the summer. The contours are at roo-ft. and $250-\mathrm{ft}$. intervals, and the representation of relief is made more striking by the use of hachures and transparent colour layers; rivers are in solid blue and woods in green. The black printing will be the same as in the popular edition The quarter-inch map is being issued with contours and layer colours in place of hill shading, red colour for main roads only, solid blue for streams, and no green wood symbol. The sample sections of the popular one-inch and the qurarter-inch maps accompanying Col. Johnston's paper are beautiful specimens of cartography, and a great improvement on the old editions, good as they were. The tourist one-inch will be useful mainly by reason of the combination of sheets which it offers. We understand that arrangements have been made to popularise these maps by having them on sale at all booksellers' and bookstalls.

\section{University and Educational Intelligence.}

CAMBRIDGE.-Gifts totalling I5ool. are announced towards the partially endowed Hoplizinson professorship in thermodynamics.

The Linacre lecture will be delivered to-day, May 6, by Dr. Henry Head on "Aphasia and Kindred Disorders of the Speech."

In connection with the installation of the Chancellor, it is proposed to present honorary degrees to the Prime Minister, Mr. Bonar Law, and several other prominent politicians. The following are amongst those selected for honorary degrees on the same occasion: Sir Joseph 